\title{
Emission from Compression Ignition Engine using Biogas Blends with Diesel as a Fuel
}

\author{
A Arul Peter
}

\begin{abstract}
A study on performance and emission of compression ignition (CI) engine has been made by utilizing biogas blends at different loads. The flow rate of biogas with air was important parameter to get the desired results. The blend of $30 \%$ with diesel was optimum which yielded optimum emission characteristics. Higher specific fuel consumption and lower brake thermal efficiency was observed when the proportion of biogas mixes with diesel in comparison with neat diesel. The out coming results from the experimental investigation exhibited reduction in NOx emission and smoke opacity. The other emissions hydrocarbon (HC) and carbon monoxide (CO) has been higher than diesel. The use of biogas as an alternative fuel in correct proportion with diesel can meet the energy demand on scarcity of conventional fuel.
\end{abstract}

Keywords : CI engine, CO, , Emission, HC, NOx.

\section{INTRODUCTION}

$\mathrm{R}$ apid consumption of conventional fuel resources to meet the demand of comfortable and economical life accelerated to find new energy sources which are renewable in nature. The renewable sources also meet the emission standard to reduce greenhouse gases directly linked with global warming. One of renewable sources to meet the demand is biogas from anaerobic digestion of agricultural and animal wastes.

\section{LITERATURE REVIEW}

Plenty of experimental investigation has been made on engines using the mix of gaseous and liquid fuel to run the internal combustion engines in recent days. Porpatham et al. $(2008,2012)$ performed experiments on petrol engine and concluded that the fuel biogas emitted less hydrocarbon and same amount of nitrous oxide. Barik et al (2014a, b) conducted experiments on diesel engine by using biogas blends with diesel which controls the emission at optimum level. Mustafi et al (2013) found the engine operated on dual fuel mode emitted higher hydrocarbon and less amount of NOX and particulate matter. Bora et al. (2013) found blends of gaseous mixture emitted less amount of hydrocarbon in

Revised Manuscript Received on December 30, 2019.

* Correspondence Author

A Arul Peter*, Associate Professor, Department of Mechanical Engineering, Vels Institute of Science, Technology \& Advanced Studies (VISTAS), Chennai, Tamil Nadu. Email: peterdmech@gmail.com

(C) The Authors. Published by Blue Eyes Intelligence Engineering and Sciences Publication (BEIESP). This is an open access article under the CC BY-NC-ND license (http://creativecommons.org/licenses/by-nc-nd/4.0/) comparison with diesel. Papagiannakis et al. (2007) and Shaoo et al (2011) conducted experiments on diesel engine with dual fuel and concluded that more amount of hydrocarbon was emitted from diesel engine at all load condition.

In this current work the investigation on emission from diesel engine operated at different load condition by using diesel and three blends of biogas mix with diesel. The outputs under biogas mix were compared with the baseline diesel operation.

\section{MATERIALS AND METHODS}

Bio gas was produced from 1:1 kitchen waste and cow dung with water by anaerobic digestion. This gas was allowed to pass through the stagnant water to remove the impurities. Carbon di oxide and hydrogen sulphide has been removed by the process scrubbing from biogas. Then the purified gas was compressed into a cylinder with axial flow air compressor. Bio gas was inducted to the engine through the inlet manifold along the air. The flow of biogas was controlled by the regulator. Diesel is injected at the end of compression.

\section{EXPERIMENTAL SETUP}

The layout of experimental setup was shown in fig 1 . The main component of the system was kirloskar single cylinder four stroke naturally aspirated direct injection diesel engine of rated power output. The details of the engine were given in table.1. Biogas from cylinder was supplied to the engine along the airflow at inlet manifold. Fuel is supplied to the inlet at 250 before top dead centre. After engine attained stable state temperature, voltage and gas inlet were taken for four conditions such as diesel, BIO 10, BIO 20 and BIO 30 blends with diesel. The properties of diesel and biogas were given in table 2 .

Table 1. Engine Details.

\begin{tabular}{|l|l|}
\hline Engine parameter & Specification \\
\hline Engine & Kirloskar \\
\hline Cylinder bore/stroke & $95 / 110 \mathrm{~mm}$ \\
\hline Displacement volume & $795 \mathrm{~cm}^{3}$ \\
\hline Compression ratio & $18: 1$ \\
\hline Fuel injection pressure & $200 \mathrm{bar}$ \\
\hline Cooling system & Air cooled \\
\hline
\end{tabular}

Table 2. Fuel Properties

\begin{tabular}{|l|l|l|}
\hline Properties & Diesel & Biogas \\
\hline Chemical composition & $\mathrm{C}_{12} \mathrm{H}_{26}$ & $70 \% \mathrm{CH}_{4} 30 \% \mathrm{CO}_{2}$ \\
\hline Density $\left(\mathrm{kg} / \mathrm{m}^{3}\right)$ & 842 & 1.06 \\
\hline Calorific value(MJ/kg) & 41.8 & 20.7 \\
\hline Cetane number & $48-66$ & - \\
\hline \multicolumn{3}{|c|}{} \\
\\
Published By: \\
Blue Eyes Intelligence Engineering
\end{tabular}




\begin{tabular}{|l|l|l|}
\hline $\begin{array}{l}\text { Auto-ignition } \\
\text { Temperature }\left({ }^{\circ} \mathrm{C}\right)\end{array}$ & 282 & 805 \\
\hline $\begin{array}{l}\text { Stoichiometric air fuel } \\
\text { ratio }\end{array}$ & 15 & 9.9 \\
\hline
\end{tabular}

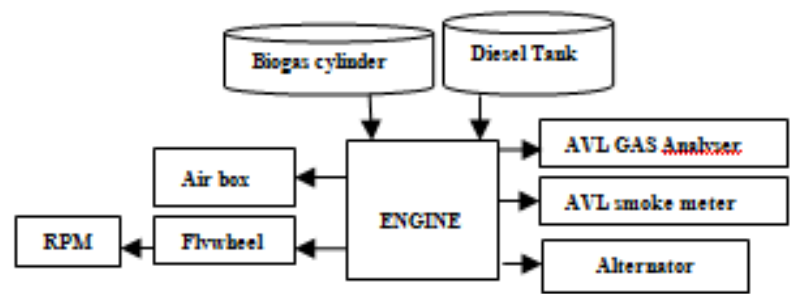

Fig. 1. Layout of experimental setup

\section{RESULTS AND DISCUSSION}

\section{A. Effect on specific fuel consumption}

Specific fuel consumption (Sfc) is one of the important parameters which decide the performance when the blends of dual fuels applied on the engine. Sfc of four different fuels at different loads taken from the engine were plotted in fig.2. It was observed that Sfc for diesel was low compared with other three combinations at all loads. The negative gradient trend was established for the particular parameter when the generation of power increased to rated condition.

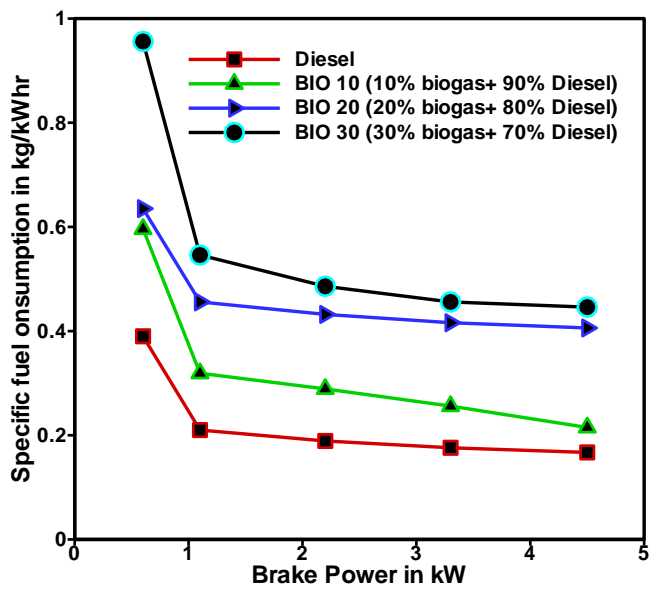

Fig. 2. Brake Power vs specific fuel consumption

\section{B. Effect on specific brake thermal efficiency}

It was observed from the plot shown in fig 3 the diesel exhibits more brake thermal efficiency at all load condition. The physical mechanism for this phenomenon was more output extraction with minimum consumption of diesel. At initial condition BTE BIO 30 was $4.8 \%$ and neat diesel $11.8 \%$. The difference in percentage has been reduced at higher loads due to the increase in flame temperature at optimal load.

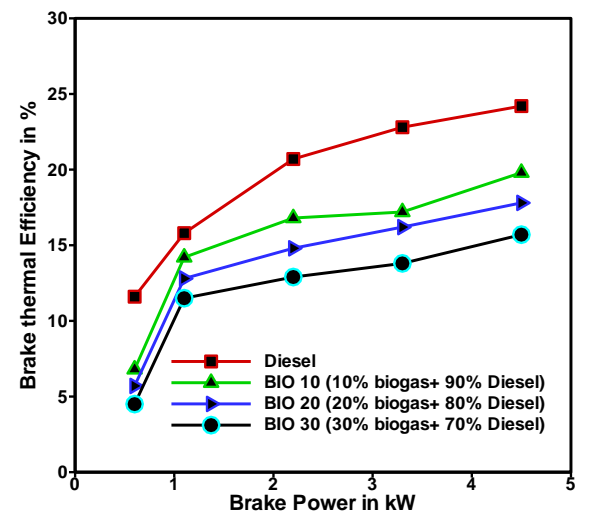

Fig. 3. Brake Power vs brake thermal efficiency

\section{Effect on NOX emission}

Fig 4 exhibits diesel emitted higher NOx at all brake powers and it was continuously increased at all load conditions. The root cause for reduction in dual fuel mode was residence of inert gas inside the cylinder diluted the flame temperature and unavailability of oxygen which reacted with hydrogen of air at higher temperature at maximum load condition. BIO 30 emitted lower NOX $22 \mathrm{~g} / \mathrm{kWh}$ at minimum brake power and $9.8 \mathrm{~g} / \mathrm{kWh}$ at maximum brake power generation.

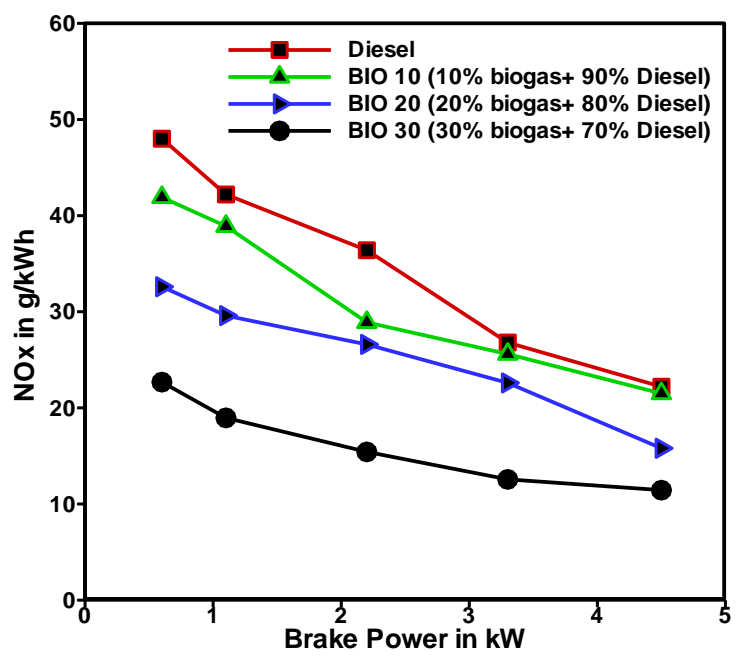

Fig.4. Brake Power vs NOX emission

\section{Effect on HC emission}

The variation of hydrocarbon emission at different brake power was shown in fig.5. The blends of biogas exhaust gas exhausted higher HC emission than diesel from minimum to maximum BP. The slow propagation of flame in dual fuel emitted the hydrocarbon due to incomplete combustion. At low brake power BIO 20 emitted $2 \mathrm{~g} / \mathrm{kWh}$ and BIO 30 was $2.22 \mathrm{~g} / \mathrm{kWh}$. The reduction of hydrocarbon at higher brake power was due to higher combustion rate and higher temperature at maximum load condition. 


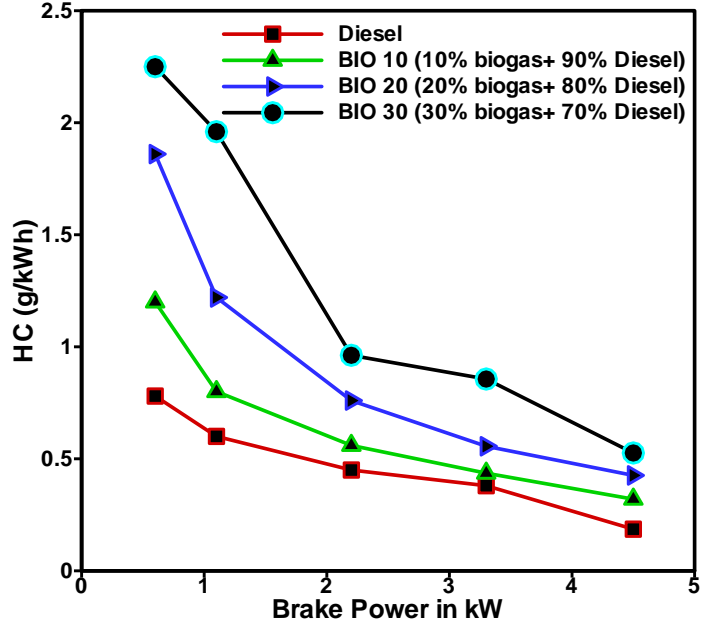

Fig. 5. Brake Power vs HC emission

\section{E. Effect on CO emission}

The spectrum of $\mathrm{CO}$ variation at different $\mathrm{BP}$ was shown in fig 6 . The front shows maximum $\mathrm{CO}$ in case of $\mathrm{BIO} 30$ due to the quenching of flame due to the inert gas like $\mathrm{CO} 2$ in biogas in comparison with diesel fuel. It is 0.376 for bio 30 blend and less than 0.3 for diesel at initial condition. At higher loads it was decreased to complete combustion of all blends and diesel.

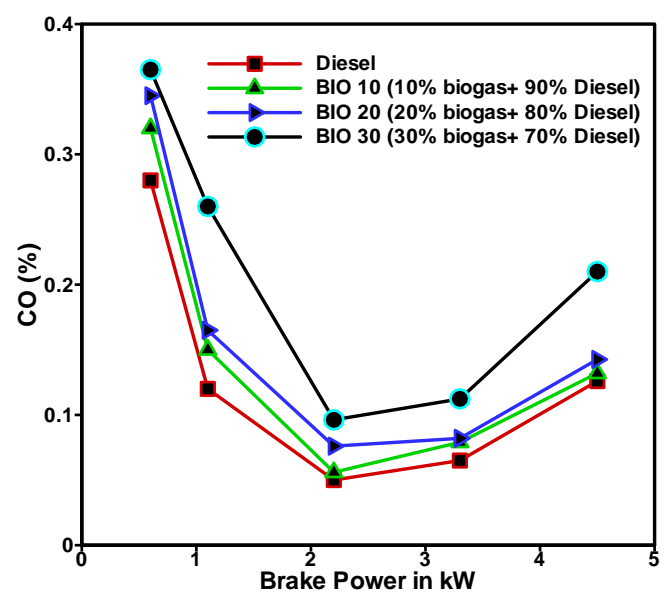

Fig.6. Brake Power vs CO emission

\section{F. Effect on smoke opacity}

Fig 7 depicted smoke opacity throughout the brake powers of engine. The heterogeneous mixture of air and diesel emitted more soot than homogeneous mixture of air and biogas blends with diesel. It was clearly indicated that reduction in soot formation occurred in homogeneous BIO 30 blend with diesel measured by AVL smoke meter.

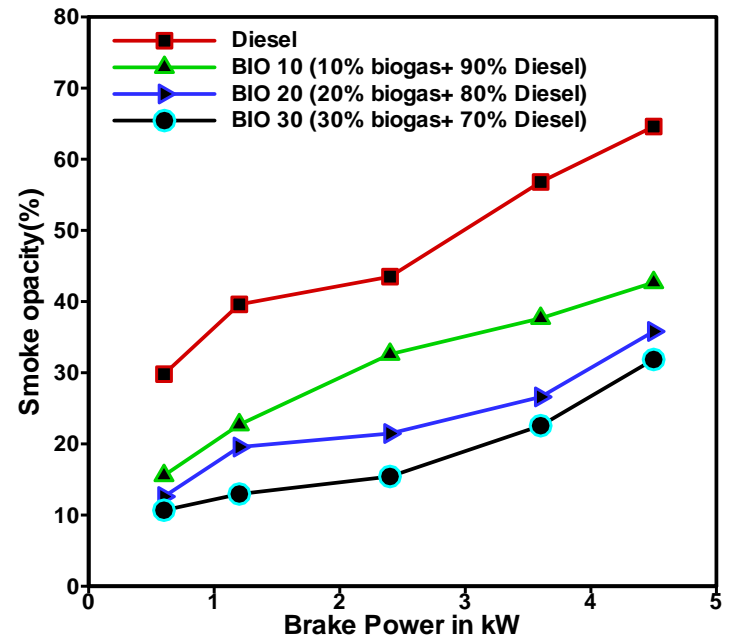

Fig. 7. Brake Power vs smoke opacity

\section{CONCLUSION}

Experiments were conducted on the CI engine by utilising diesel and blends of biogas with diesel. It was observed that BIO 20 has optimum mix at all BP of the engine. At full load it consumes less sfc, $0.75 \mathrm{~g} / \mathrm{kWh} \mathrm{HC}$ emission and $0.13 \%$ of $\mathrm{CO}$ emission. Biogas mix with diesel will meet the energy demand and electricity generation in future.

\section{REFERENCES}

1. D.Barik, S.Murugan, "Investigation on combustion performance and emission characteristics of a DI (direct injection) diesel engine fueled with biogas-diesel in dual fuel mode," Energy vol 72, 2014a, pp 760-771.

2. D Barik, S Murugan, "Simultaneous reduction of NOx and smoke in a dual fuel DI diesel engine,” Energy Convers Manag, vol. 84, 2014b, pp. 217-226.

3. BJ. Bora, BK. Debnath, N. Gupta, UK. Saha, N. Sahoo, "Investigation on the flow behaviour of a venturi type gas mixer designed for dual fuel diesel engines," Int J Emerg Technol Adv Eng, vol.3, 2013, pp.202-209.

4. NN. Mustafi, RR.Raine, S.Verhelst, "Combustion and emissions characteristics of a dual fuel engine operated on alternative gaseous fuels. ," Fuel, 2013, vol.109, 2013, pp. 669-678.

5. E. Porpatham, A. Ramesh, B. Nagalingam, "Investigation on the effect of concentration of methane in biogas when used as a fuel for a spark ignition engine. Fuel Issue.87, vol. 9, 2008, pp. 1651-1659.

6. E. Porpatham, A. Ramesh, B. Nagalingam, "Effect of compression ratio on the performance and combustion of a biogas fuelled spark ignition engine," Energy Convers Manag vol. 95, 2012, pp. 247-256.

7. N.H.S.Ray, M.K.Mohanty, R.C. Mohanty, "A Study on Application of Biogas as fuel in Compression Ignition Engines," International Journal of Innovations in Engineering and Technology," Issue 1, vol. 3, 2013. pp. 239-245.

8. BB. Sahoo, "Clean development mechanism potential of compression ignition diesel engines using gaseous fuel in dual fuel mode. Ph.D thesis, Centre for Energy, 2011, IIT Guwahati, India.

\section{AUTHORS PROFILE}

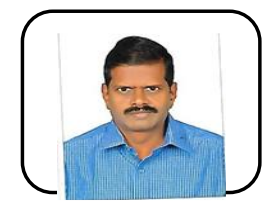

resources.
Dr. A. Arul Peter, is an Associate Professor in Department of Mechanical Engineering, VISTAS, Chennai. He had done his research work on "Study of heat and mass transport through concrete exposed to elevated temperatures" in IIT Roorkee. His areas of interests are FEA, CFD, I.C Engines, heat and mass transfer and alternative energy 